Article

\title{
Imitate: Remediating Glass as an Artistic Medium for Material Imitation
}

\author{
Jessamy Kelly $\mathbb{D}$ \\ School of Design, Edinburgh College of Art, The University of Edinburgh, Edinburgh EH3 9DF, UK; \\ jessamy.kelly@ed.ac.uk
}

Received: 30 November 2018; Accepted: 26 February 2019; Published: 4 March 2019

\begin{abstract}
Glass has a unique ability to imitate other materials; cross-pollinating with other disciplines to refresh and recreate itself. The creative possibilities of creating glass that imitates other materials such as ceramic, paper, metal, wood, stone, plastic and semi-precious stones are vast. The assertion of this paper is that the use of imitation is a necessary and definitive act within creative artistic practice. Following a range of historical examples to set the context for this article, a range of contemporary glass artists that use glass as a medium for imitation will be introduced and documented through a series of artists case studies. Finally, I will present my current practice-based research into glass as a medium for imitation. I will discuss the material testing and research that has been carried out and introduce two new bodies of artworks that I have developed based on the theme of glass as an artistic medium for material imitation.
\end{abstract}

Keywords: glass; ceramics; milk glass; porcelain glass; imitation; materiality; cross-cultural pollination; remediation

\section{Introduction}

Author and poet, Katie Stevens discusses the history of imitations and our relationships with them: 'I want to give fake its clothes back. I want to take back the language around the fake, around what this word and its friends have meant historically, socioeconomically, and psychologically, and what they mean today ... For too long humans have given copies, imitations, substitutes, faux this and false that, short shrift' (Stevens 2018, p. 1). Should true originality be placed on an artistic pedestal versus an interpretation of the original which has been inspired by and derived from it?

The starting point for this research project occurred during my doctoral research (completed in 2009), when I first came across and compared the historical connections between the disciplines of glass and ceramics. In reviewing the field closely, I was led to consider a range of historical glass artefacts including milk glass-artefacts created in white glass to imitate Chinese porcelain (see Figure 1) and Hyalith glass-artefacts created in red and black glass with gold enamel to imitate red Chinese and black Japanese lacquerware (see Figure 2). Both types of glass were featured in the Corning Museum of Glass, 2011 Exhibition: East meets West: Cross cultural influences in glassmaking in the 18th and 19th centuries. This exhibition started a chain of thought which in 2012, led me to select a range of key examples of historical glass that imitated other materials for study and use them as a foundation for my own creative artistic practice. "The allure of the "exotic" and the appeal of the materials unknown to the West-such as hard paste porcelain and lacquer-stimulated the production of glass objects imitating the treasured eastern imports. Western scientists did not know porcelain was a clay-based substance and mistakenly assumed it must be a vitreous one. Therefore, their efforts to reproduce porcelain resulted in the production of a variety of opaque white "milk glass" objects $\ldots$ at the same time, finely painted and gilded opaque black and red glasses emerged-mainly from glasshouses in northern Bohemia — that imitated red Chinese and black Japanese lacquer objects in 
style and iconography' (CMOG 2011). Thus, these pieces are imitations, copies of an original idea however as they are created in a different medium they themselves are original.

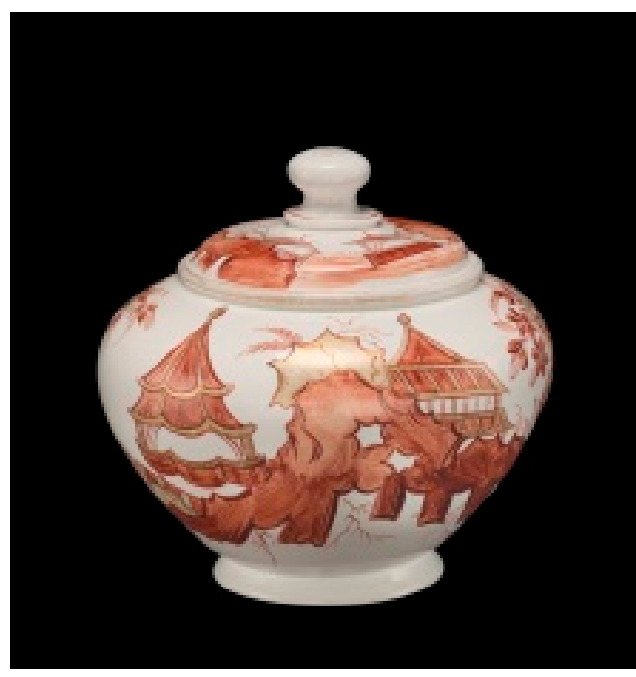

(a)

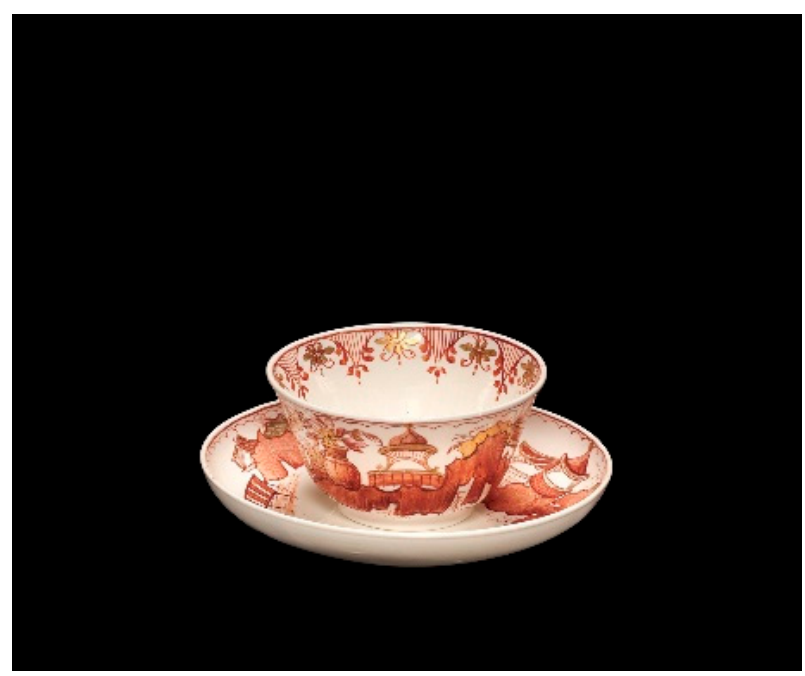

(b)

Figure 1. Image courtesy of the Corning Museum of Glass (CMOG): Sugar bowl with cover (a) and Teacup and saucer (b), Lattimo Glass, Francesco Vezzi, Venice, Italy, (1720-1724), blown glass, enameled. H. 7.2 cm; Diam. 10.4 cm; Lid: H. 3.4 cm; Diam. 7 cm.

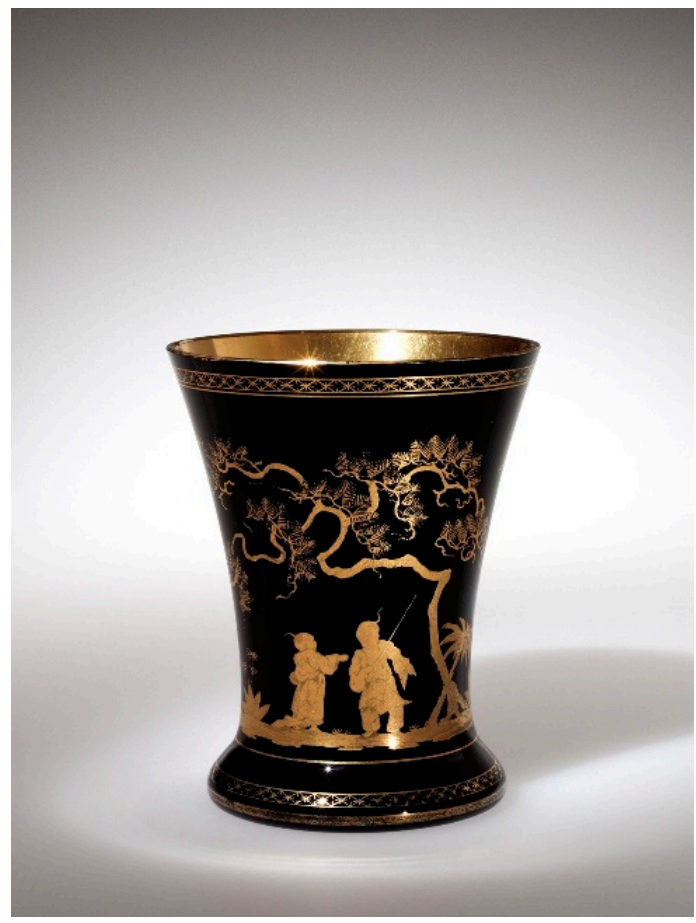

Figure 2. Image courtesy of the Corning Museum of Glass (CMOG): Hyalith Beaker, Bohemia (about 1825-1840) blown glass, lustre. H: $10.8 \mathrm{~cm}$; D (rim): $8.6 \mathrm{~cm}$.

\subsection{Porcelain Glass}

Opaque or 'opaline' glasses can be traced back to Egyptian times and have been used throughout history in various forms. The Venetians first produced a 'lattimo' porcelain glass in the mid-15th century, a white glass developed by adding tin and lead lime to the glass batch (see Figure 3). In his book on Murano Glass Gianfranco Toso discusses one of the first historical references to porcelain glass: 'In 1457 the Great Council further permitted Iacopo d'Angelo ... to work "cristallo and porcelain glass in his 
furnace"' (Toso 2000, pp. 47-48). In the 17th century, European glassmakers expanded the production of 'porcelain glass' to imitate Chinese porcelain, as glass was a far cheaper material to produce. The Germans produced a 'porzellanglas' or 'milchglas' (Bray 1995, p. 177) and in 1663, Crafft introduced 'beinglas' to northern Europe, produced with bone ash (Loibl 2008, pp. 67-68). 'In the 1690s, Perrot also made opaline glass based on porcelain designs in Orleans, France' (Kingery 1986, p. 171).

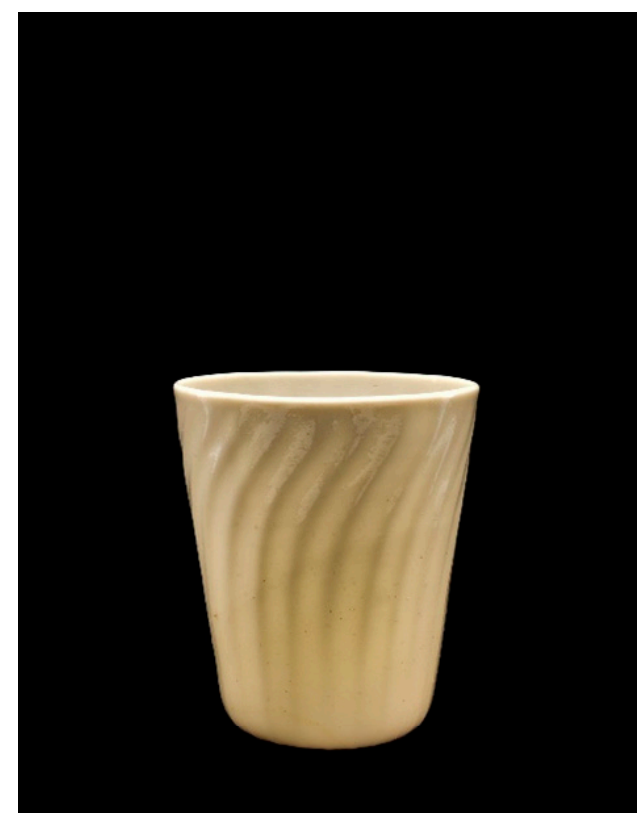

Figure 3. Image courtesy of the Corning Museum of Glass (CMOG): Lattimo Glass beaker, Europe (1700-1799) blown glass. H: $8.8 \mathrm{~cm}$; D (rim): $7.7 \mathrm{~cm}$.

During this period, the race to master porcelain production in Western Europe was obsessive and extremely competitive. In the face of many failed attempts to create hard paste porcelain, milk glass was an affordable imitation of a material that was hailed as the white gold of its time. Porcelain was viewed as the ultimate commodity; largely because its production techniques were unknown in Europe and it had to be imported at great expense from the Far East. Led by key scientists and alchemists of the time the race to master porcelain was a serious business. An intensive period of research ensued, catalysed by the introduction of chemical research and scientific principles to the study of ceramics. 'In the late 16th century, Italy led the way with a soft paste porcelain or pâte tendre called "Medici" porcelain; France had the first break through with the development of a commercial soft paste porcelain at Sèvres; finally in 1708 this was rivalled with the development of a hard paste porcelain in Meissen, Germany' (Kingery 1986, pp. 154-63).

Scientists and artisans have continued to develop their own theories and artistic goals extending the parameters of the field. The chemical theories which emerged during this period have greatly influenced the development of ceramic and glassmaking techniques; which have gone on to have far reaching applications for industry and the studio craft movement. The influence of chemistry and alchemy on the development of glass and ceramic production established the foundation for many of the new material technologies and processes that we know today.

This trend of imitation extended into the 18th and 19th century, whereupon extravagant vessels were made of translucent white glass to imitate Chinese porcelain. 'Independent decorators often painted and gilded both glass and porcelain. The Europeans' chinoiserie style of decoration featured gilding, asymmetrical forms, unusual perspectives, and Oriental motifs' (www.cmog.org, accessed 28 October 2018). This pair of milk glass vases painted by enameller Jean-Francoise Robert is an excellent example of glass emulating Chinese porcelain forms, however with a more European styling to the painted enamel work (see Figure 4). 


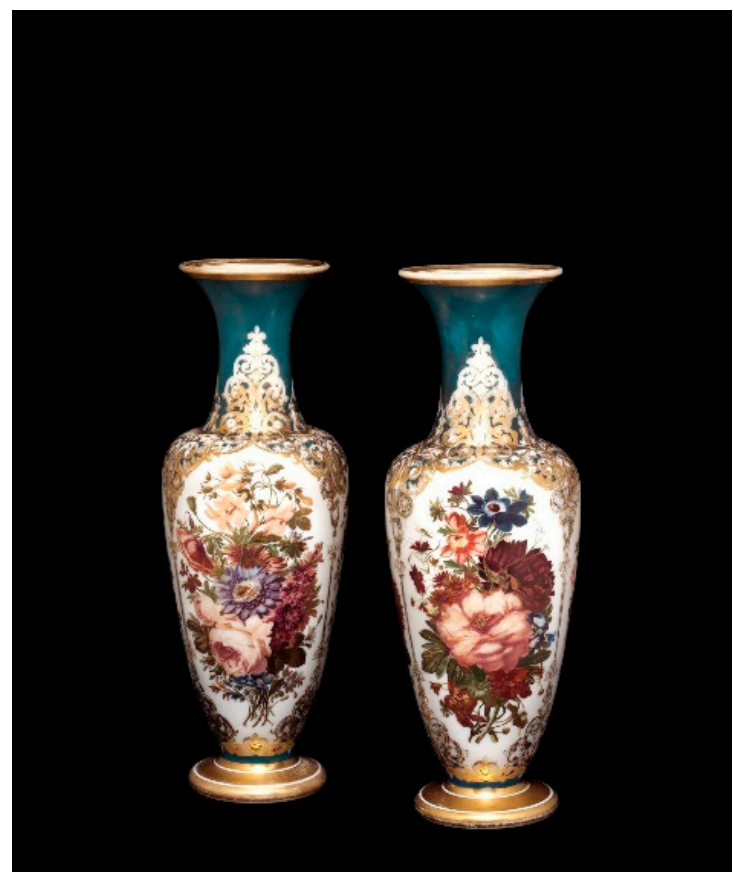

Figure 4. Image courtesy of the Corning Museum of Glass (CMOG): Opaline Vases, Verreries et Cristalleries de Baccarat, blown glass, painted by Jean-Francoise Robert (about 1845-1850). H: 59.7 cm; D (max): $20.9 \mathrm{~cm}$.

Another significant example of porcelain glass was created in 1886, when a blown opaque white glass vase made in imitation of the Morgan Vase. A Chinese porcelain vase, made history when it was sold by the estate of Mary Morgan for $\$ 18,000$ US dollar (see Figure 5). 'Copies of the vase in both glass and porcelain were rushed to market as soon as the story of the sale was published' (www.cmog.org, accessed on 28 October 2018).

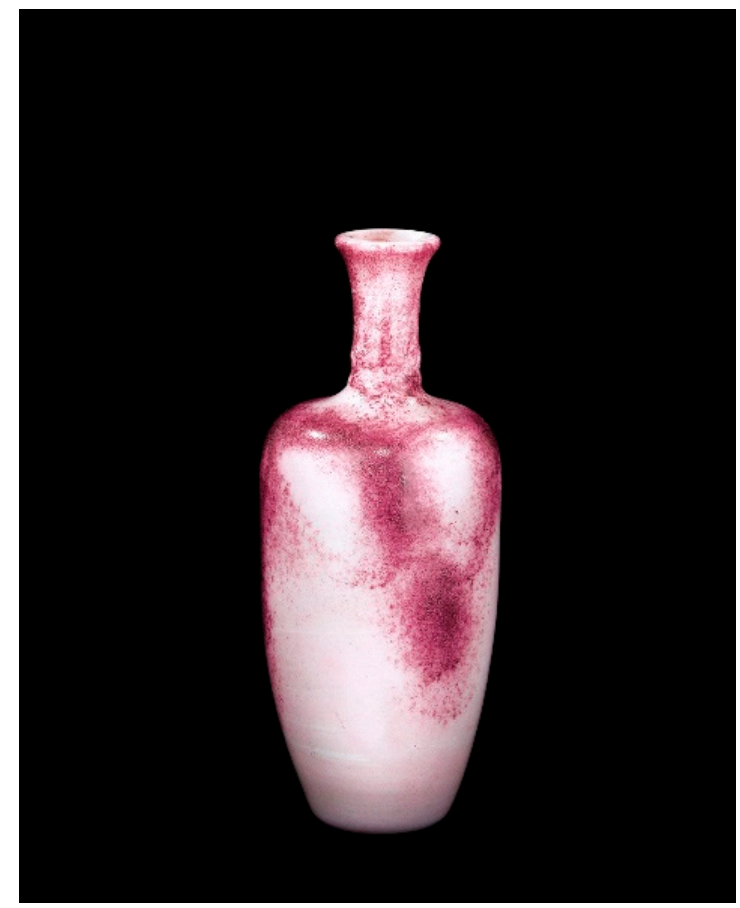

Figure 5. Image courtesy of the Corning Museum of Glass (CMOG): Morgan Vase, 1886-1888, Boston \& Sandwich Glass Company, US, blown glass. H: $19.2 \mathrm{~cm}$; D (max): $8.1 \mathrm{~cm}$. 
The historical precedence of this range of porcelain glass vessels are of significant relevance to my own research, as they draw a close technical and aesthetic link between glass and ceramics. The creation of glass objects that directly imitate porcelain is clearly evident in these artefacts. As a researcher and glass artist, I find the story of porcelain glass extremely captivating and this precedence strongly resonates within my work. The creation of glass objects that directly imitate porcelain continues to inspire me to harness the aesthetic purity of semi-translucent white, milk glass in the creation of my kiln cast glass artworks. Opaline white glass is an extremely versatile material. At times it can be densely opaque and solid, its surface completely non-refractive. Yet, it can be worked into a delicate opalescent, whereupon light refracted through the 'Tyndall effect' makes the object appear to be blue from the side, or often red to orange as light passes through it, I often use the opalescent effect in my work (see Figure 6).

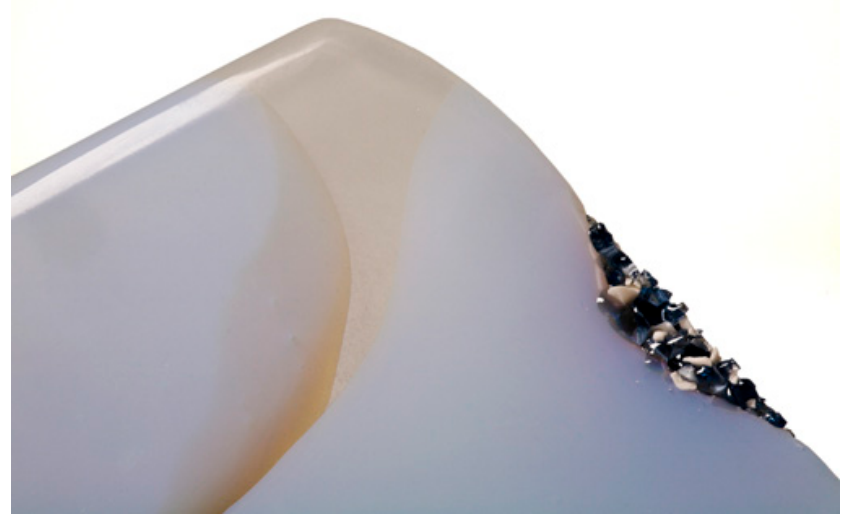

(a)

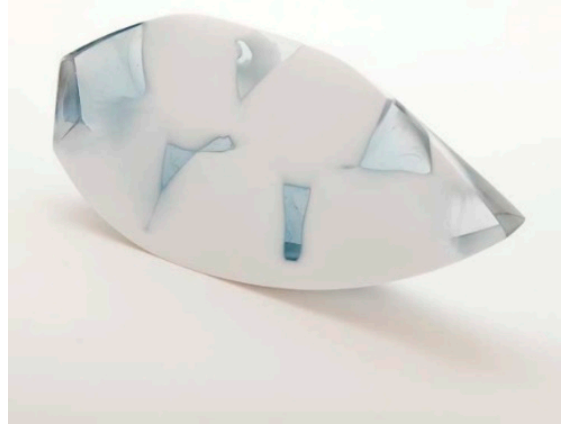

(b)

Figure 6. Image courtesy of Jessamy Kelly: (a) Segment, kiln cast opaline glass, 2009, Photo credit: David Williams. H: 15 cm; W: 22 cm; D: 7 cm. (b) Wedge, kiln cast opaline glass, 2009, Photo credit: Studio 41. H: $30 \mathrm{~cm}$; $: 40 \mathrm{~cm}$; D: $20 \mathrm{~cm}$.

Following my doctoral research (2004-2009), I focused on the medium of opaque white glass, however, the first opportunity that I had to fully explore porcelain glass as a way of imitating ceramics was in the summer of 2014 when I was invited to participate in the International Glass symposium at the Rona Glass Factory, in the North of Slovakia. Initially, I was asked to prepare an independent project and send through technical drawings. I decided to base my project on porcelain glass and based my forms on classical Chinese porcelain vessels to be blown in opaque white glass. Working with the factory, the aim was to create a series that represented how white glass has the ability to imitate Chinese porcelain, the aim of this project was for the completed work to be viewed as a contemporary representation of porcelain glass. Three of the large-scale pieces were hand painted with a Chinese porcelain decoration which was copied and applied onto the surface in platinum enamel, working around a distorted silhouette with in and out surface depressions. One piece remained clear whilst one transitioned into a piece that faded out into a white enamel colour (see Figure 7). In all of the works a smaller scale replica piece was placed within each piece; imitating the exterior form. A second series (see Figure 8) was created in completely clear glass; the voids of the opened ended forms were filled with small polished glass semi circles and a single smaller replica of the exterior form. The refractive qualities of the piece were very simple and reflected the outside view within the piece. I decided not to use white glass to compare this series with the other; to juxtapose the materiality of the clear and white glass. Within my work I enjoy the viewers challenge to consider its materiality and the process by which it was made. Is it porcelain or glass? Is it kiln cast or blown? This secrecy and hidden meaning within my artefacts drive and inspires my practice. 


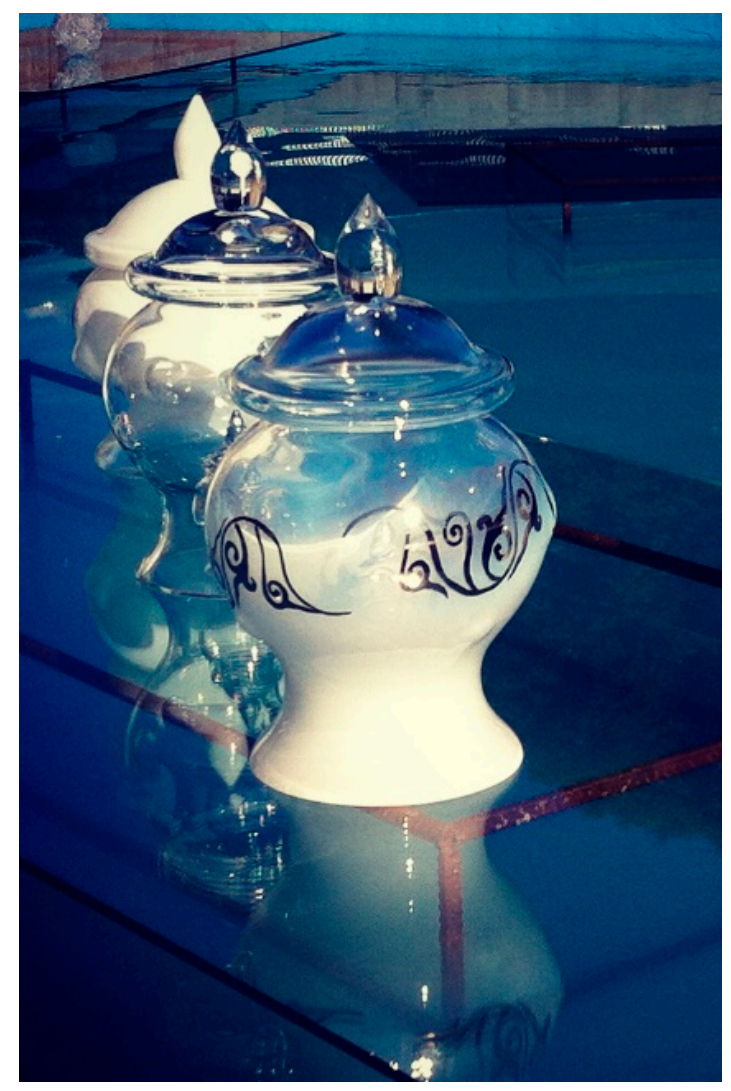

Figure 7. Image courtesy of Jessamy Kelly: Milk Glass (2014), opaque blown, cut \& polished glass, with platinum enamel. Photo Credit: The artist. H: $58 \mathrm{~cm}$; D: $32 \mathrm{~cm}$ (each).

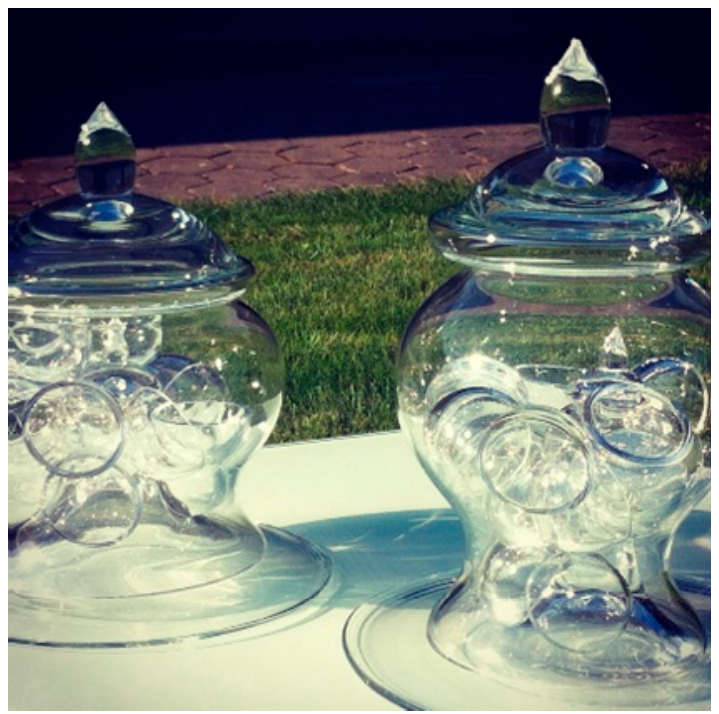

Figure 8. Image courtesy of Jessamy Kelly: Distilled (2014), clear blown, cut \& polished glass, assembled \& glued, Photo Credit: The artist. H: $58 \mathrm{~cm}$; D: $32 \mathrm{~cm}$ (each).

\subsection{Semi-Precious Stones}

In addition to imitating porcelain, glass is renowned for its ability to imitate other materials such as the opaque, lustrous qualities of semi-precious stones; which dates from ancient Mesopotamia and whose imitation extended throughout history. Gianfranco Toso discusses this in his text on Murano (the glass island of Venice): 'In March 1233 the Giustizieri were obliged to prohibit the Venetian goldsmiths from making gold mountings for imitation coloured and clear glass gemstones. This probably amounts to the 
oldest information about the production of false jewels in Venice' (Toso 2000, p. 26). To add to this, I refer back to the Corning Museum of Glass collection: 'Throughout the late 18th and 19th century there were a number of European gem engravers who not only created their own works based on ancient styles and prototypes, but who also made extremely refined copies of known ancient gems ... a skilled gem engraver who was familiar with working in glass as well as hardstone. Such gems, whether ancient or modern, were avidly collected by connoisseurs on the Grand Tour, who hoped to make a personal association with the ancient world by acquiring its remains' (CMOG, accessed 28 November 2018). During the renaissance there was a mania for hard stones such as agate, chalcedony, jade and lapis lazuli. As discussed, Venetian glassmakers began to imitate these stones; creating many examples of imitation, such as this 16th century Venetian Calcedonio glass bowl (see Figure 9). This craze continued to spread throughout Europe and experiments with colouring glass continued throughout the 18th and 19th century; as glass makers sought to make their own innovative colour and finish in glass.

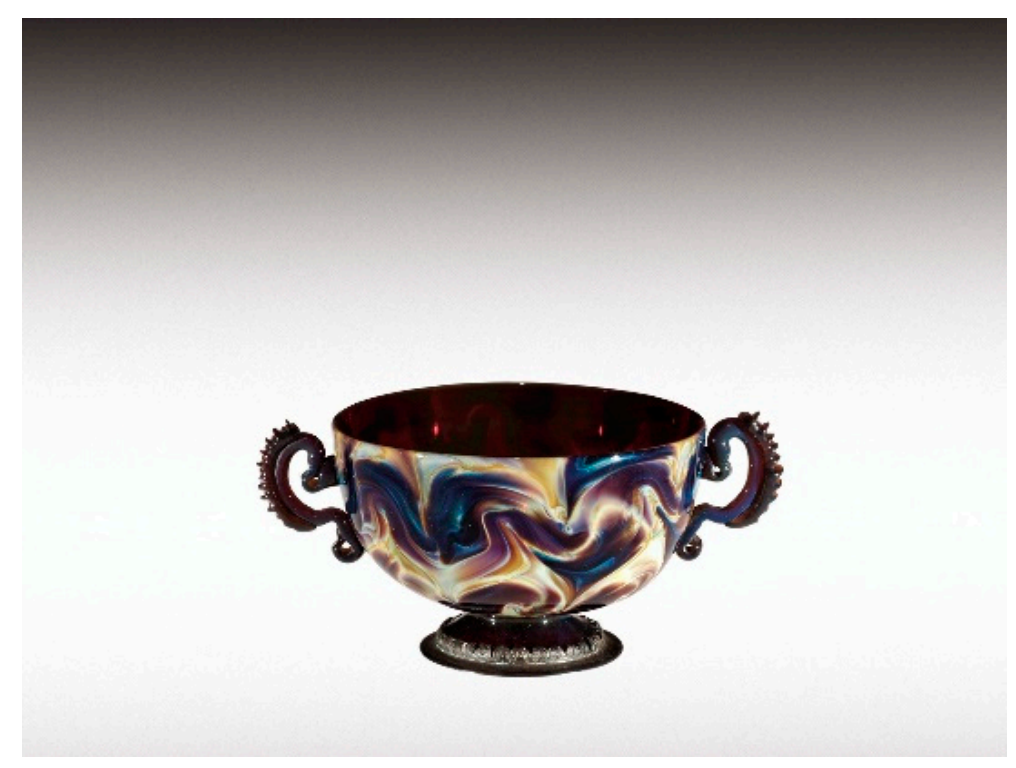

Figure 9. Image courtesy of the Corning Museum of Glass (CMOG): Calcedonio glass bowl, Italy, Venice (1600-1699), blown glass. H: $5.9 \mathrm{~cm}$; W: $12.6 \mathrm{~cm}$; D (rim): $8.9 \mathrm{~cm}$.

Within my own practice, this understanding of the rich historical context of glass history and its unique ability to be technically worked and expertly coloured, inspired a new range of material testing. This process led directly to the careful creation of a palette of colours and finishes that imitate semi-precious stones. From this, a new body of glass gems were created; imitating agate, amethyst, jade, emerald and lapis lazuli (see Figure 10). The works are made from kiln cast glass which has been lost wax cast, and then diamond cut and brush polished to a sheen, they purposefully appear to be quite raw and uncut in areas.

I started to look for other examples of glass that imitated other materials. Western alchemy plays a large part in understanding the history and origin of early glassmaking. Historian Maddalena Rumor discusses how alchemists created materials of greater value from cheaper base materials, including the use of glass to counterfeit and imitate semi-precious stones: 'The earliest examples of alchemical texts, two Greek papyri written in the late 3rd century BCE, contain recipes for dyeing of precious metals, stones and purple. The incentive was clearly to obtain something of seemingly greater value out of cheaper materials ... It consists mainly in a series of instructions on the manufacture of colored glass (presumably to counterfeit precious stones), and a handful of other tablets, all dated between the 12th and the 7th centuries BCE. These focus on various sorts of dyeing procedures, often involving the dipping of pebbles, base glass or a mix of minerals into a dying liquid, to make them resemble precious stones or metals' (Rumor 2018). 


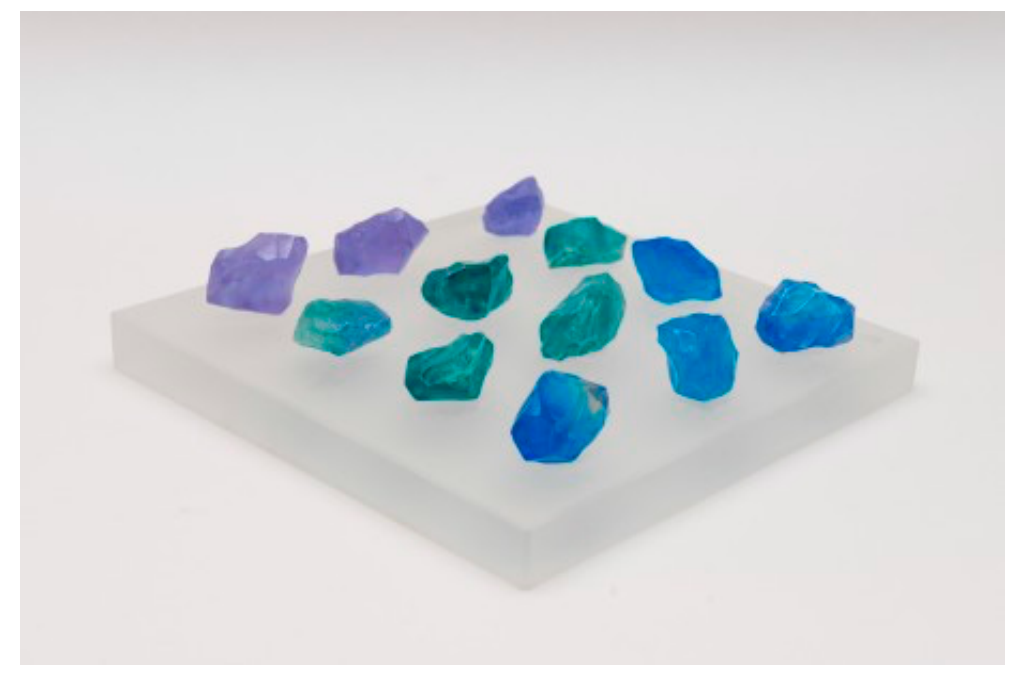

Figure 10. Image courtesy of Jessamy Kelly: Imitate (2018), blue glass, cobalt and copper cobalt, jade and purple glass to imitate semi-precious stones-lapis, jade and amethyst, kiln cast glass, cut. Lead crystal. Photo credit: Marzena Ostromecka. H: $8 \mathrm{~cm}$; D: $30 \mathrm{~cm}$; W: $30 \mathrm{~cm}$.

'In the 17th century crystal and ruby glasses were made to look as if they were made from naturally occurring rock crystal and precious ruby stones; a high value material which was ranked alongside porcelain' (Von Kerssenbrock-Krosigk 2008, p. 123). This demonstrates the revered luxury status of glass throughout history and the ability of glass to blend itself with other materials to create something new. I have grown to appreciate the unique quality of glass to blend and imitate, in order to strengthen this assertion, I will discuss some historical examples of the way glass has imitated other materials throughout history. As discussed above, a Venetian Calcedonio blown glass bowl from the Corning Museum of Glass collection, is a particularly apt example of a marbled glass made to imitate the semiprecious stone chalcedony (see Figure 9). 'The glass known as calcedonio was popular at both ends of Venice's "golden age": about 1500 and the 18th century. It is an inhomogeneous glass colored with silver. Specialty glasses undoubtedly added luster to Venice's image as the glassmaking center of the world during the Renaissance' (Gudenrath 2016).

A gold ruby goblet (see Figure 11) that was shown as part of the 'Glass of the Alchemists' exhibition at the Corning Museum of Glass (CMOG 2008), is also a strong example to support this historical review: 'Gold ruby is arguably one of the most beautiful colours of glass. Beyond its aesthetic qualities, there is an alchemical connotation: Since ancient Greek times, descriptions of the sorcerers' stone agree that it was believed to be a red substance and the key to the transmutation of metals, principally the making of gold' (CMOG 2013a). 'Whoever discovered how to colour glass red must have thought himself to be on the right track to attaining the ultimate goal of alchemy' (CMOG 2013b).

In the early 19th century, Bohemia was a centre for new developments in glass that imitated other materials such as marble, agate, lapis and lacquerware. In 1828, Friedrich Egermann patented his process for producing Lithyalin glass, an opaque marbled product that was designed to resemble semi-precious stones (see Figure 12). Shortly after this period, Agatine glass (see Figure 13) was developed which had a very distinctive colour and surface finish close to agate. A Lapis glass was also created during this period by Curt Schlevogt, made to look like lapis lazuli. 


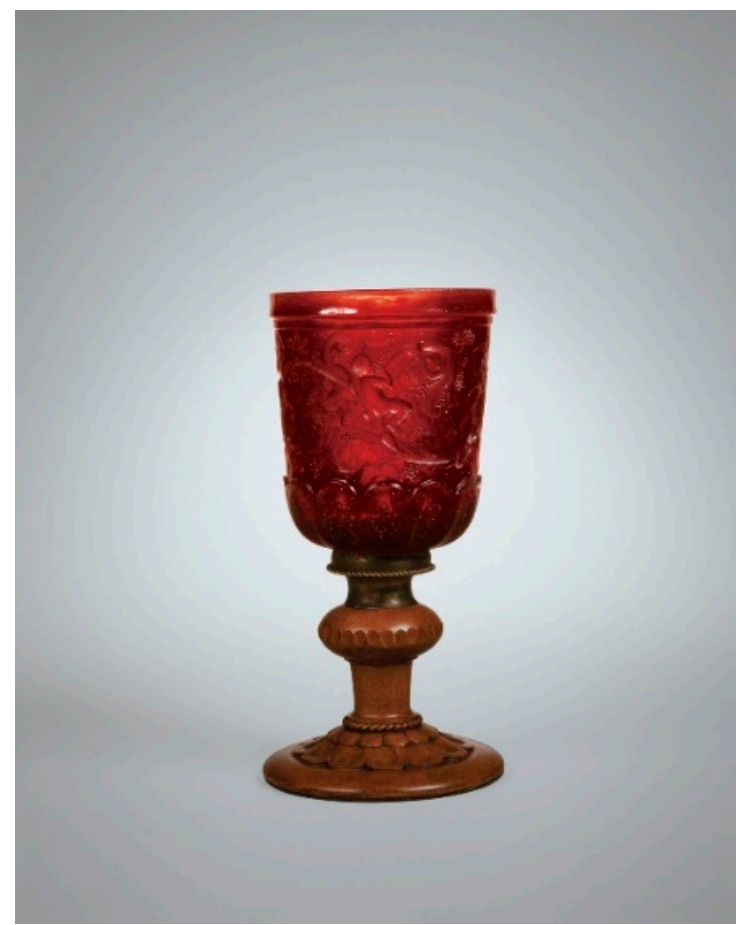

Figure 11. Image courtesy of the Corning Museum of Glass (CMOG): Gold Ruby Glass Goblet, Potsdam (1690-1700), blown glass, cut \& engraved. H: $24.1 \mathrm{~cm}$; D (rim): $11.7 \mathrm{~cm}$; D (foot): $12.9 \mathrm{~cm}$.

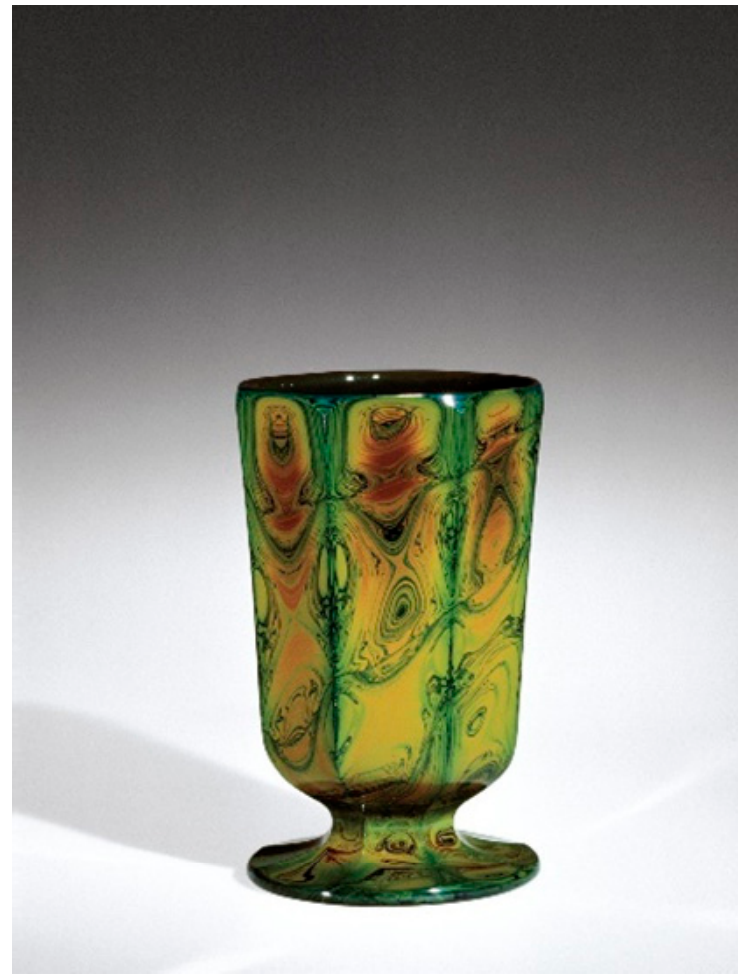

Figure 12. Image courtesy of the Corning Museum of Glass (CMOG): Lithyalin Beaker, Workshop of F. Egermann, Manufacturer, Novy Bor, Bohemia, 1830-1850, blown glass. H: 11 cm; D: $6.6 \mathrm{~cm}$. 


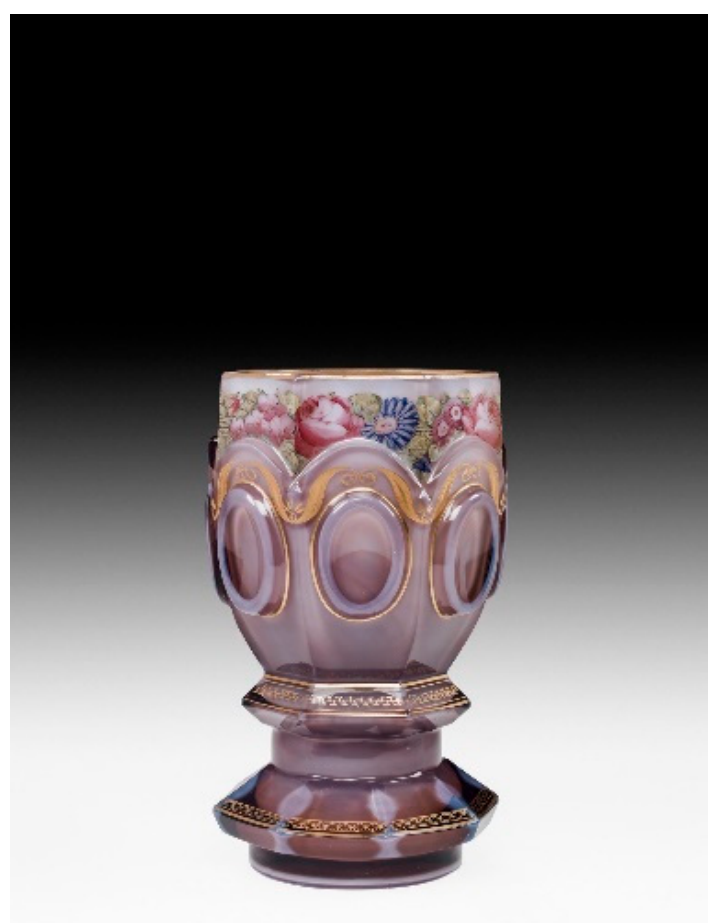

Figure 13. Image courtesy of the Corning Museum of Glass (CMOG): Agatine beaker, dated around 1835-1840, from Southern Bohemia, blown glass, cut and enameled. H: $14.5 \mathrm{~cm}$; D: $8.9 \mathrm{~cm}$.

In the 18th century, Hyalith glasses were produced to imitate red Chinese and black Japanese lacquerware. These glasses were mainly produced in Southern Bohemia, around 1825 onwards. Similar to porcelain glass, the allure of lacquerware as a new material to the West influenced the production of objects that imitated the orient. A Hyalith glass beaker (see Figure 2) shown as part of the 'East Meets West: Cross-Cultural Influences in Glassmaking in the 18th and 19th Centuries' exhibition at the Corning Museum of Glass, in 2010 is also of great interest to this project. In reviewing this period of intense material innovation, where previously the driver for imitation would have been financial gain to create an illusion of rarity and value; it is possible to re-value these artefacts. The growing appreciation of the unique ability of glass to imitate other materials has greatly influenced this research project. Thus, glass viewed as an artistic medium for material imitation supports the assertion that the use of imitation and the remediation of other forms and materials is a necessary and definitive act within creative artistic practice.

\subsection{The Portland Vase}

Around the turn of the 1st century BC/AD cameo cut glass vessels were made, the most famous vase of this style being the Portland vase which is housed in the British Museum, London. This vase is an excellent example of Roman cameo glass, which has served as an inspiration to many glass and ceramics makers from the 18th century onwards. It was famously copied and recreated in ceramic by Josiah Wedgwood, who devoted many years to copying the vase in black and white ceramic jasperware. The ceramic Wedgwood version is housed in the Victoria \& Albert Museum, London and is an interesting example of a glass artefact which has been imitated in the medium of ceramics. In the 19th century, a competition to duplicate the Portland vase was won by glass maker Philip Pargeter who made a copy, it was engraved by John Northwood (see Figure 14). The imitation and background of this artefact is of great interest and still there is much consternation over how the original was made. Most recently, Richard Whiteley, a renowned Australian glass artist has been leading a group of researchers to investigate Roman cameo glass using a high-resolution 3D scanner. They believe 
that cameo pieces such as the Portland Vase were not actually blown as previously claimed but are examples of pressed pâte de verre glass, a kiln casting technique which dates back to ancient Egypt.

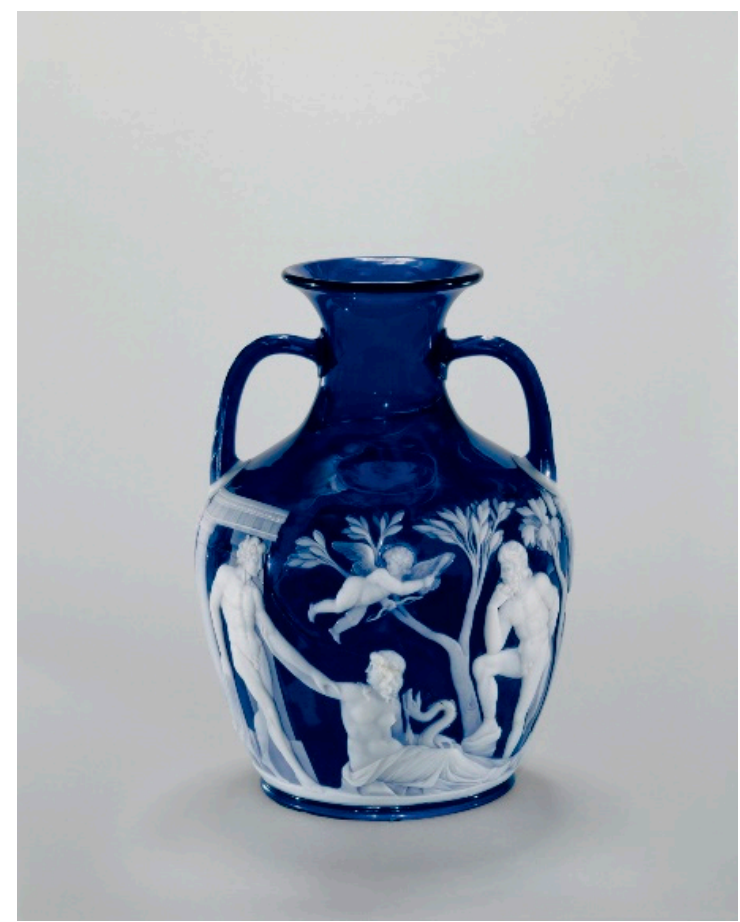

Figure 14. Image courtesy of the Corning Museum of Glass (CMOG): John Northwood (Engraver) \& Philip Parageter (Proprietor of the Red House Glass Works), 1873-1876, blown glass. H: 25 cm; D (body): $18.2 \mathrm{~cm}$.

\section{Case Studies of Contemporary Glass Artists}

A series of case studies were carried out on a diverse range of contemporary studio glass artists that create glass artworks that imitate other materials, they were selected and categorised by the material and processes they imitate. The case studies described in this section will examine the individual approaches and style of the artist's work which are used to exploit the visual effects of glass as a medium for artistic imitation. These examples have helped to inform the research project and aid the positioning of this research in the contemporary field of practice; as well as giving an in-depth insight into the approach of the artists and the ways they approach their work. The following four glass artists were selected for interview: Edmond Bryne, Graeme Thyer, Choi Keeryong and Wendy Fairclough.

In reviewing the work of these artist through the lens of imitation, it is timely to discuss a recent essay by Amy Gogarty entitled 'Remediating Craft' which discusses how practitioners are working in new ways to repurpose craft, actively moving away from a fine art system for valuing their work. In this essay Gogarty discusses remediation as defined by Bolter and Grusin as a way to understand new media: 'Mediums borrow-repurpose or refashion-examples from within their own history, as a form of homage or critique, or as a formal rhetorical device to reinterpret older media. What becomes clear is that all mediation is a form of remediation. Media constantly comment on, reproduce or replace other media, operating within webs of cultural meaning and social relations' (Bolter and Grusin 1999, p. 55).

Gogarty describes how remediation can be applied to craft-based disciplines, with specific reference to clay: 'If the goal of remediation is to refashion or rehabilitate other media ... remediation can be understood as a process of reforming reality ... In its ability to simulate other materials, clay has long remediated other materials and objects ... as metallurgy developed and came to be associated 
with elite containers, ceramics adapted to imitate metal forms ... In the nineteenth century, lustre wares mass produced for middle class markets imitated costly silver and its less costly imitation, electroplate. Nineteenth-century industrial production churned out low-cost consumer goods in great abundance, a phenomenon that raised concern among design reformers, class-conscious conservatives and social activists alike... the very notion of cheaper material imitating costly ones smacked of deceit, bad faith and an attack on the social order ... The influence of these philosophers and critics undermined notions of craft materials remediating in a positive way, a situation that continues to infect late-modernist values dominant in many areas of craft practice' (Gogarty 2007, pp. 95-97).

To extend this argument, Craft theorist Peter Dormer discusses the use of homage in the crafts: 'The receptiveness to the knowledge and achievement that an object represents and demonstrates is quite often not communicable in words but is communicable by making stuff of one's own. Which is why people who like objects appear to like making similar objects of their own. It seems that craftspeople make things out of homage to the objects that already exist... there is the desire to gain understanding through making' (Dormer 1997, pp. 151-52). It is of great interest, that Gogarty's perspective formed on how clay imitates other media to create a new remediation of itself, and Dormer's view on the act of homage to gain a deeper understanding of a craft discipline, draws direct parallels to the examples discussed in this paper.

\subsection{Edmond Bryne}

Edmond Bryne is an Irish glass artist based in Surrey. He often creates glass that has a visual resemblance to other mediums such as ceramics and textiles, he also employs a weathering technique which directly references ancient glass artefacts. He works predominantly in mould blown glass, making use of a range of materials to make his moulds including cotton textiles, plaster, clay, metal, sand and paper to create texture in his work.

Bryne describes his technique: 'This process requires perishable materials so they break away to release the glass as there are many undercuts in the texture they create. The glass takes on the movement and gesture of the materials used. For example, the folds and creases of the textiles are emulated by the glass as it takes their form in the mould ... I am interested in the "pure" qualities of glass but not in their refined form. I don't believe in a traditional hierarchy of aesthetics for this material. It was a relief to discover that glass didn't have to look like glass' (Bryne 2018).

This process allows Bryne to subtly reveal the marks of making and capture the gestures and movement of the process. He uses a range of semi-transparent and opalescent colours in his work, creating fine lines of crazing and a delicate ageing effect by applying a kaolin/water patina to his glass which creates a weathered surface (see Figure 15).

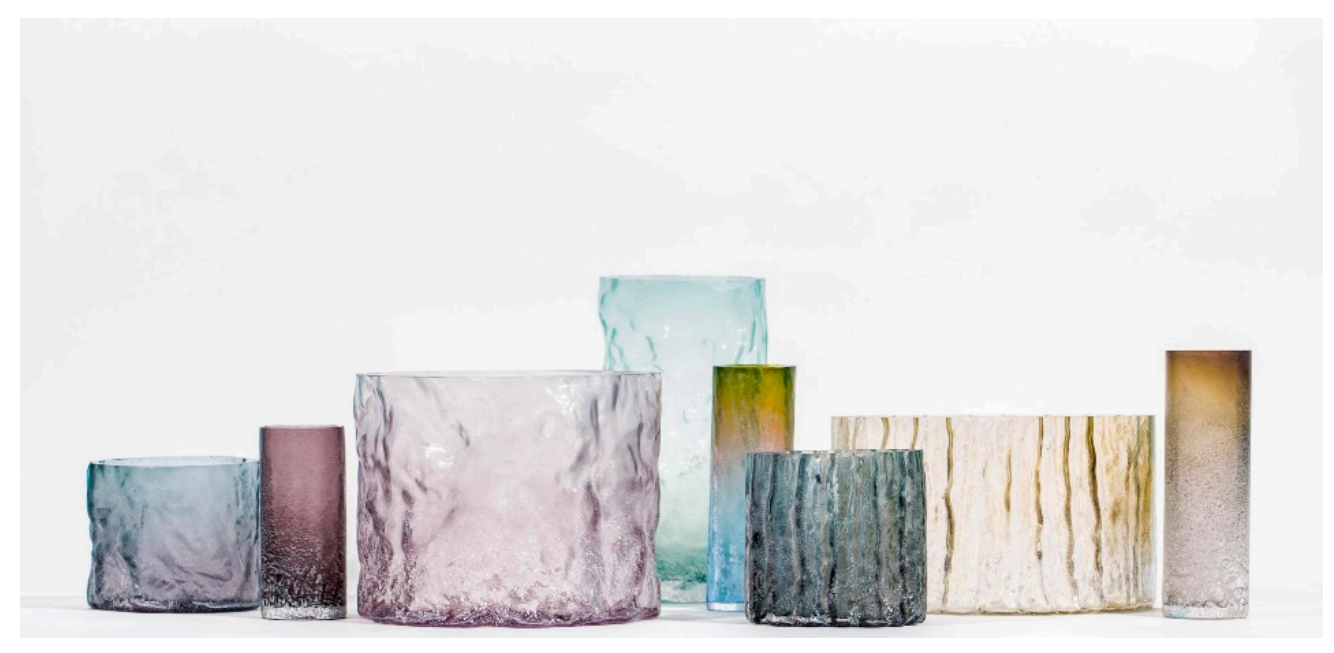

Figure 15. Image Courtesy of Edmond Bryne: Metameric Landscape, blown glass with kaolin patina, Photo: Beytan Erkman. H: 60 cm; D: $130 \mathrm{~cm}$. 
'I do a lot of drawing. My visual inspiration comes through interpreting the marks, gestures and energy of my drawings into glass. I'm intrigued by objects that have a resonance from the past. I add patina and cracks to the glass surface to recreate the weathering of ancient Roman glass. Subconsciously this places my vessels in the past becoming artefacts of the mind' (Bryne 2018).

His glossy and finely textured 'Moon Jar' series (see Figure 16) are based on the iconic Korean Moon Jar, for him they are a reinterpretation of an ancient artefact that has inspired him to emulate a ceramic aesthetic in his work. They are technically challenging and require a large team of people to create them. For me they are an excellent example of how glass can be used to imitate other materials to create cross-cultural references and a unique artistic approach to glass making.

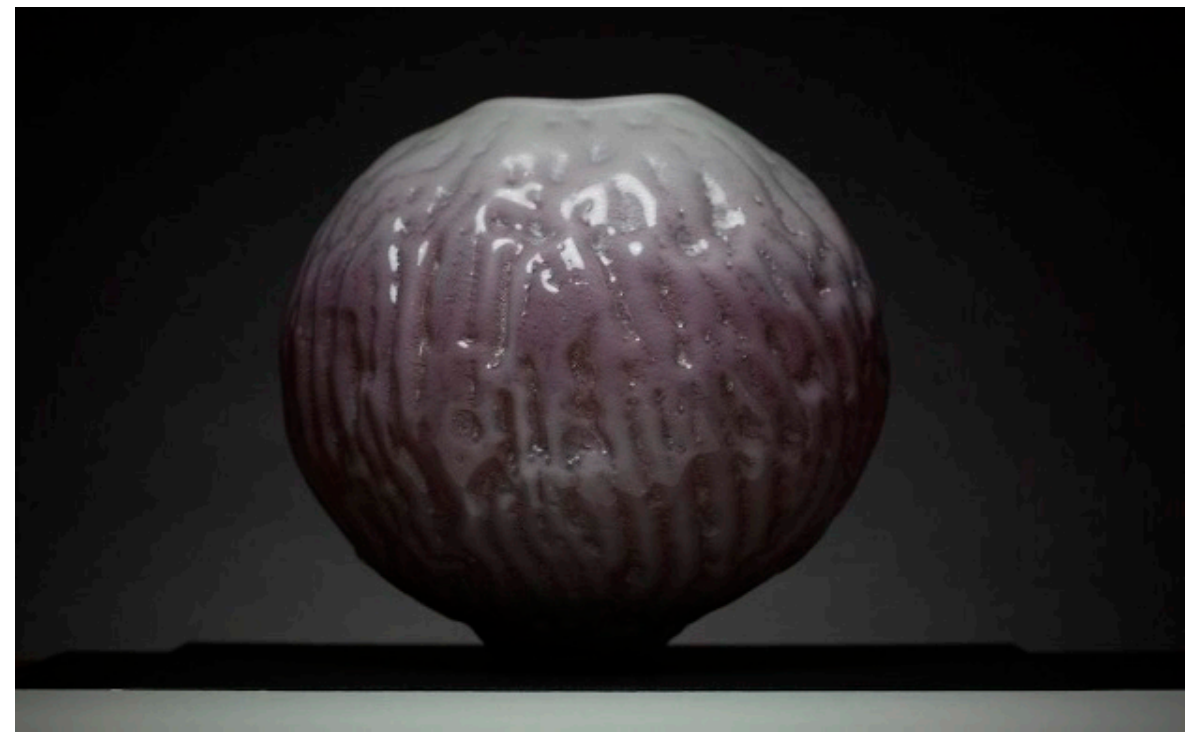

Figure 16. Image Courtesy of Edmond Bryne: Maroon Moon Jar, blown glass with kaolin patina, Photo: Peter Rowen. H: 40 cm; D: $40 \mathrm{~cm}$.

Bryne references Scandinavian organic modernist glass as being extremely influential on his work, in particular Timo Sarpaneva's Eruption vase (1964) and Tapio Wirkkala's Ice, Avena and Stellana (see Figure 17) vases and bowls are both excellent examples of glass being used to resemble and imitate other natural mediums, Bryne remediates materials such as wood or ice, which is strongly emulated in the textured surface of these works. There is strong visual reference to Wirkkala's design classics apparent in the work of both Bryne and Thyer (who will be introduced below).

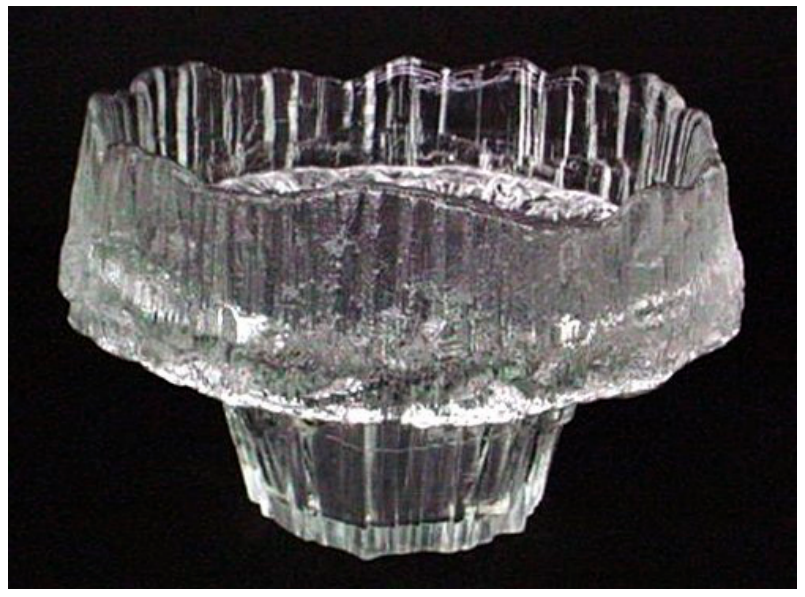

Figure 17. Image courtesy of the Corning museum of Glass: Tapio Wirkkala, Stellana Bowl, Ittala, Finland (1968). H: $17.2 \mathrm{~cm}$; D: $27.6 \mathrm{~cm}$. 


\subsection{Graeme Thyer}

Graeme Thyer is an English glass artist based in the North West of England. He works predominantly in glass, often taking reference from other materials and processes. Working in both blown and cast glass, he creates artefacts that draw from a wide range of mediums emulating and remediating materials such as charred wood, raku ceramics or the fine Japanese artistry of 'Kintsukuroi' (golden repair). Thyer is intrigued by the historical position of glass in both the East and the West, he sees a duality that is perhaps at the core of this article. To him glass is a material that is revered in the West but in the East, it was seen as a cheaper material to copy and imitate more expensive, luxury materials; he questions this in his work:

Eastern civilisations have only recently started in the manufacture of art glass, it is seen more as a mass-produced commodity, rather than the revered art form of their potteries. Within the past the Western World inherited the cultural enjoyment of glass from the Romans, while the East saw glass as an inferior material to their porcelain and a cheap imitation of precious stones. To replicate glass, with the theories of Eastern craftsmanship produces a whole new outlook on the material of glass, whilst creating objects that appear to replicate their counterpart (Thyer 2018).

Thyer's kiln cast glass artwork entitled 'Charcoal' (see Figures 18 and 19) fits well within this article, wooden forms were turned and then charred by hand, to create wax models from, the work was then lost wax cast in dense black glass; the final piece takes on the imprint of the origin material but is imbued with new qualities in its new form of glass, when viewed the pieces are contradictory and makes the viewer question the artefacts origin, bringing new perspective to the field.

Thyer's blown glass works 'Raku' (see Figure 20) are technically advanced, he employs a complex overlay technique which involves the pre-production of delicately fused glass islands made from fine glass powders which are then picked up hot, rolled up and worked onto a carefully prepared coloured overlay form. Fine crazing is achieved by dipping the whole piece in water which introduces risk to the making process. The working time on these pieces is significant and Thyer employs a painterly aesthetic to achieve his expertly tuned colour mixes, the overall effect creates completely unique artworks with a definitive nod towards a ceramic tradition. For Thyer this series explores the purity of the Eastern Raku-ware, with the Western approach to studio art glass.

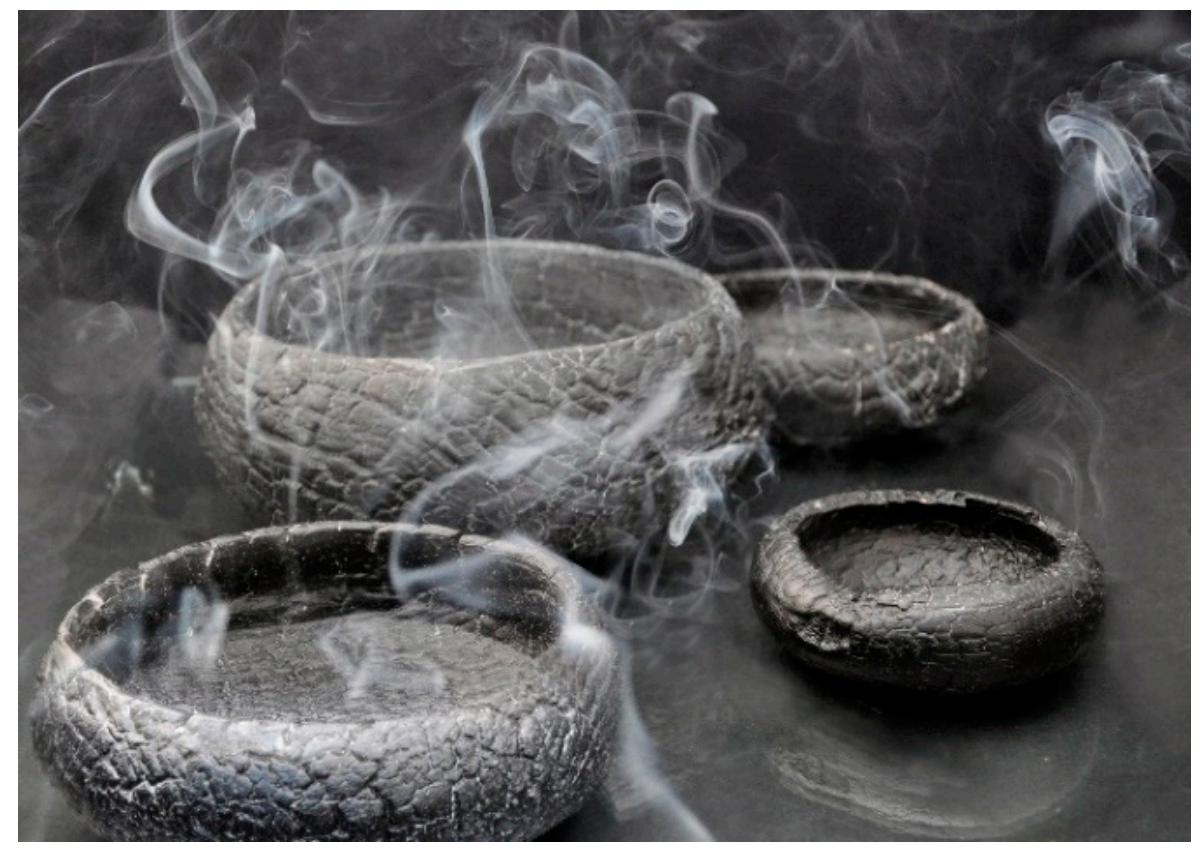

Figure 18. Image Courtesy of Graeme Thyer: Charcoal, 2011, kiln cast glass, photo credit: the artist, varying sizes. Max H: $20 \mathrm{~cm}$; D: $10 \mathrm{~cm}$; $\min H: 4 \mathrm{~cm}$; D: $4 \mathrm{~cm}$. 


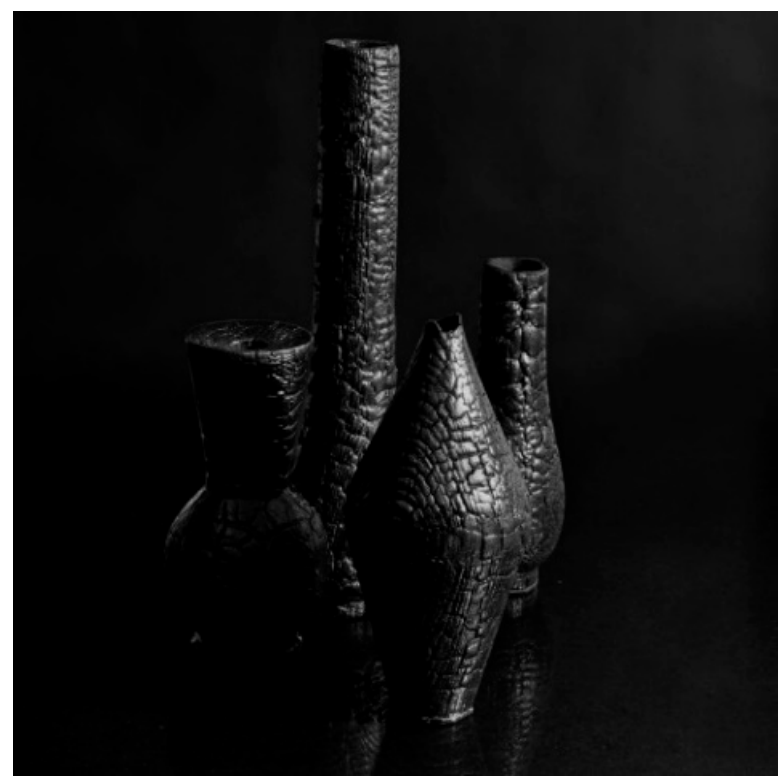

Figure 19. Image Courtesy of Graeme Thyer: Charcoal, 2011, kiln cast glass, photo credit: the artist, varying sizes. Max H: $30 \mathrm{~cm}$; D: $10 \mathrm{~cm}$; $\operatorname{min~H:~} 8 \mathrm{~cm}$; D: $4 \mathrm{~cm}$.

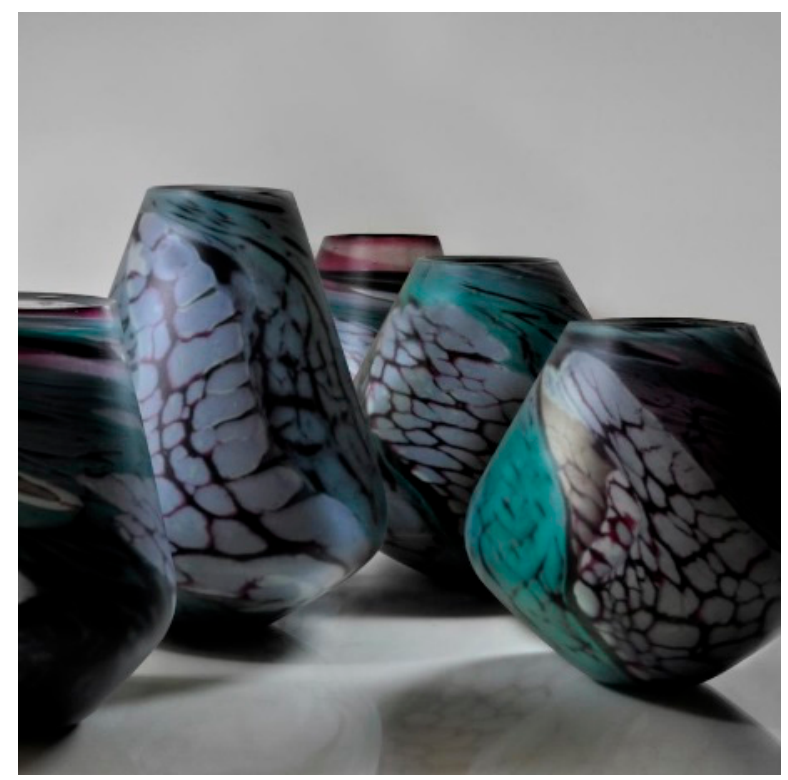

Figure 20. Image Courtesy of Graeme Thyer: Raku, 2013-2014, blown glass, photo credit: the artist, varying sizes. Max H: 25 cm; D: $15 \mathrm{~cm}$; $\min \mathrm{H}: 20 \mathrm{~cm}$; D: $16 \mathrm{~cm}$.

Thyer's most recent work, 'Redeemed' (see Figure 21) takes reference from the Japanese technique of 'Kintsukuroi', also known as golden repair, it is a method of restoration usually carried out on broken ceramic artefacts. Thyer uses this theory to repair glass vessels with precious metals, which have shattered during production. 'Any creation, failure or success are made at the cost of the environment. So restoring these failures, should produce outstanding objects which pioneer in beauty. It is this understanding of the traditional Japanese aesthetics of wabi-sabi which allows me to create artefacts with no practical goal, as they are not made for aesthetic enjoyment, but created to be a symbol of a process of understanding; bringing the viewer's conscious mind closer to the reality of themselves' (Thyer 2018). 


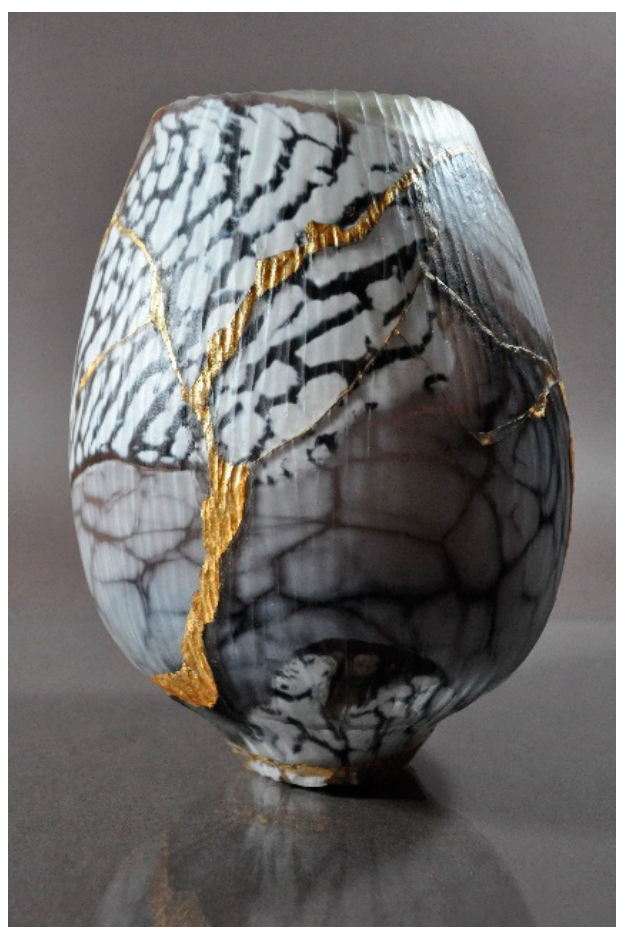

Figure 21. Image Courtesy of Graeme Thyer: Redeemed, blown glass, glue \& gold leaf, photo credit: the artist. H: $28 \mathrm{~cm}$; D: $18 \mathrm{~cm}$.

Thyer's glass vessels directly borrow the content of ceramics vessels, momentarily confusing the viewer, to me they are not a deception but more of a homage to technique and history. Thyer references historic ceramic theories from the East as having significant influence on his creative practice, in viewing his work in this paper alongside a range of historical and contemporary references it is possible to see that although highly individual his work is of significant interest to this article and the field of study. Since 2017, Thyer and I have been working together on a creative collaboration, a range of initial tests and prototypes have been produced based on the theme of porcelain glass. We are intrigued by the impact this historical precedence can have on contemporary studio art glass practice.

\subsection{Keeryong Choi}

Keeryong Choi is a Korean glass artist based in Edinburgh. He works in both blown and kiln cast glass, and uses a range of materials, such as porcelain, gold foil and gold lustre to create unexpected juxtapositions in his art work. During his doctoral studies at Edinburgh College of Art, Keeryong worked on a body of work entitled the 'Korean Glass Project' (see Figures 22 and 23), a series of blown glass carefully inlaid with fine lines of coloured glass frit juxtaposed with found porcelain objects. 'This work was greatly influenced by the cross-cultural differences he experiences: As a Korean artist my work is significantly inspired by my personal experience of being in a state of in-between-ness, in terms of my current cultural location, given that I have lived in Edinburgh for approximately thirteen years but was born, brought up and lived in South Korea for thirty years. For my glass artwork, I created, deliberately, a pseudo Korean-British or British-Korean image that is viewed as a Western or Eastern image or a mix of both cultures. I am hoping that the cultural ambiguity inherent in my artwork challenges viewers, sometimes and creates uneasy feelings in them when they look at it' (Choi 2018).

In particular, Keeryong directly references a Qing dynasty white milk glass vase (1736-95) as having particularly influence on his creative practice. This piece directly imitates porcelain and is overlaid with dark blue glass and engraved in the cameo fashion. Keeryong actively remediates the medium of porcelain through his glass artefacts and is very conscious of his choice of materials 
in his work, and the associations and careful juxtapositions he constructs. 'My choice of materials reflects the historical, cultural, and symbolic meaning inherent in the history of glass and porcelain, both in the East and West. Although glass in the West, and porcelain in the East, developed under different cultural and historical circumstances, the unique distinctions in both cultures becomes more abstract and blurred as the interplay between the two cultures became more complicated, dynamic and interactive. The reason I chose glass and porcelain as my primary materials is to highlight the tensions, conflicts, uncertainty and negotiations which, I believe, are a by-product of the cultural exchanges and relationships between the West and East. Furthermore, my intention in combining the two materials and creating unfamiliar images is to invoke a sense of the cultural in-betweenness in viewers, in both Britain and Korea' (Choi 2018).

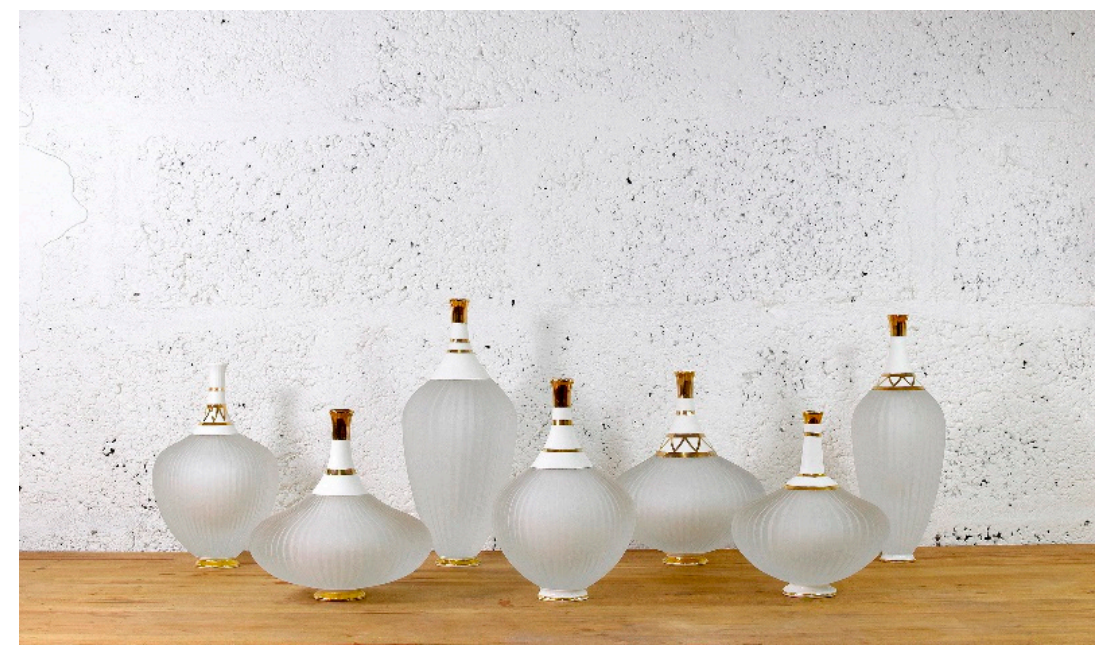

Figure 22. Image Courtesy of Keeryong Choi: Korean Glass (2015): blown glass, second-hand English manufactured porcelain, gold lustre, Photo credit: The artist, varying sizes. Max H: 32 cm; max D: $15 \mathrm{~cm}$.

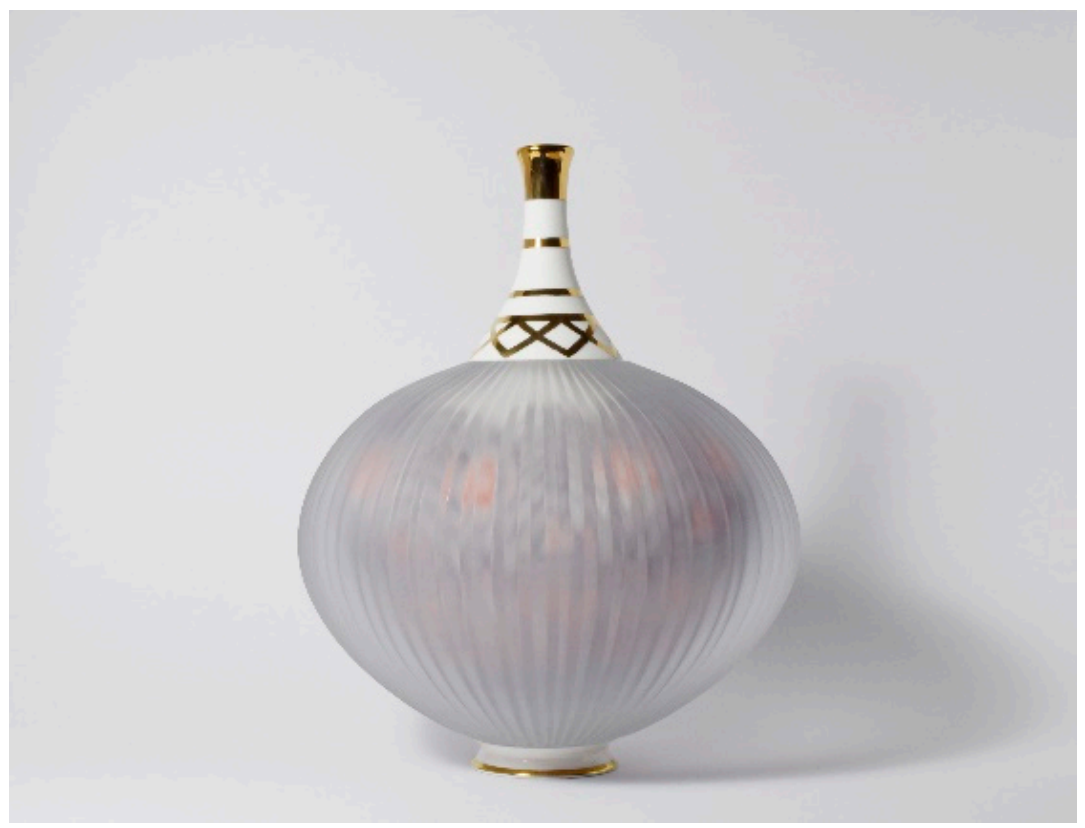

Figure 23. Image Courtesy of Keeryong Choi: Korean Glass 2 (2016): blown glass, second-hand English manufactured porcelain, gold lustre, Photo credit: The artist. H: $28 \mathrm{~cm}$; W: $20 \mathrm{~cm}$. 
His most recent works the 'Daam Dah' (2018) series (see Figure 24), is a range of small kiln-formed glass containers, which he deliberately creates with very fine bubbles on the casted glass surface. Bubbles in a kiln cast are often regarded as a failure for glass artists, by using small frit size glass and skipping the bubble soaking time during the kiln firing, he then applies a fine inlay of gold foil into the bubbles. 'I aim to celebrate the instability and uniqueness, which can be resolved through reflective negotiation within a given situation in the process of glass making' (Choi 2018).

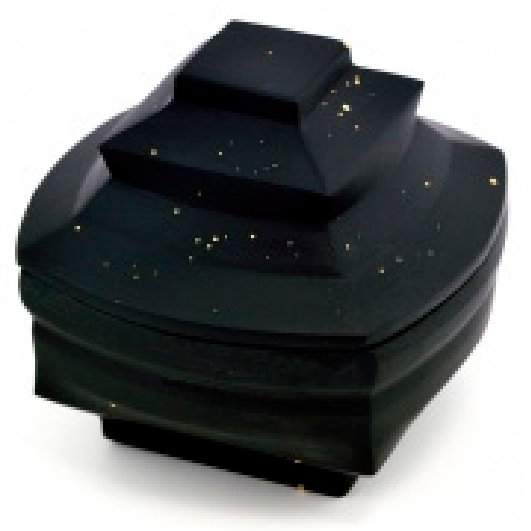

Figure 24. Image Courtesy of Keeryong Choi: Daam Dah (2018), kiln formed glass, 23.5ct gold leaf, Photo: The artist. H: $8 \mathrm{~cm}$; D: $7 \mathrm{~cm}$; W: $7 \mathrm{~cm}$.

In conversation with Keeryong it was possible to discuss the theme of this research paper. He concurs with the concept of glass as a medium that imitates others materials, he directly discusses this within his doctoral thesis, describing how he took direct references from lattimo (milk glass) into his practice, which he discusses: "The history of porcelain and the vogue in Europe for "Chinoiserie" design, allowed me to develop a unique artistic perspective that inspired the development of a body of artworks-Korean Glass (2010-2017) and Daam Dah (2018). For example, in the history of European porcelain, the invention of lattimo is the earliest evidence of an attempt to imitate the Orient and its art/objects, and the properties of the foreign material and colour in Western countries. Hence, in my view, the history of lattimo needs to be seen as the beginning of the vogue for "Chinoiserie" in Europe. I combined not only the physical properties of white opaque glass and porcelain, but the historical aspects of them to provide an experience of in-betweenness in the viewer. They allowed me to develop artistic perspectives into cross-cultural contexts related to the individual's experience of the aesthetics of the cultural uncanny' (Choi 2018).

\subsection{Wendy Fairclough}

Wendy Fairclough is a New Zealand glass artist, based in South Australia. She works in both blown and kiln cast glass. In her early work she was greatly influenced by the still life paintings of Georgio Morandi and the paintings of Colin McCahon, who inspired Fairclough to imbue different metaphorical meanings into everyday objects. In conversation with Fairclough about the topic of this article we discussed her work in detail: 'My objects are almost facsimiles in a way. But are not meant as imitations of a material or object per se. More as analogies or simply to add a more dreamlike quality to the object. I do like to utilize the qualities of glass to make things we are used to seeing in another material or context because it somehow removes them a step away from reality yet still acts as a metaphor for the object or an idea associated with the object' (Fairclough 2018).

The subtle palette of her earlier work such as 'Four shades of white' (see Figure 25) and 'Softened Landscape' (see Figure 26) are understated, articulated in a range of opaque and milky white glass, this series of work lend itself to this article and the connections I see between the work of artists like Fairclough and the historical precedence of milk glass. Fairclough's more recent work such as 'Enfold' and 'Threads' are especially distinctive of her approach, she has a well-defined style which is seen in 
her visual language, the 'Enfold' series is especially resonant, resembling objects that have been bound and wrapped in fabric, the original form is masked but still visible below the surface.

Fairclough transforms domestic objects into glass, which she represents in still life format curating like a painter the composition with a sensitive and close reference to light and subtle colour use. Although she does not directly imitate, she views her work as direct casts of objects which have been imbued with new meaning, when worked in glass. 'In my most recent work I am drawn to objects and activities that are intimately familiar for most human beings in every culture or religion. The focus is on what we have in common regardless of external differences and extends to an interpretation of gestures and objects associated with the ingenuity and creativity of the human mind and hand in meeting basic human needs such as food, warmth and shelter' (Fairclough 2018).

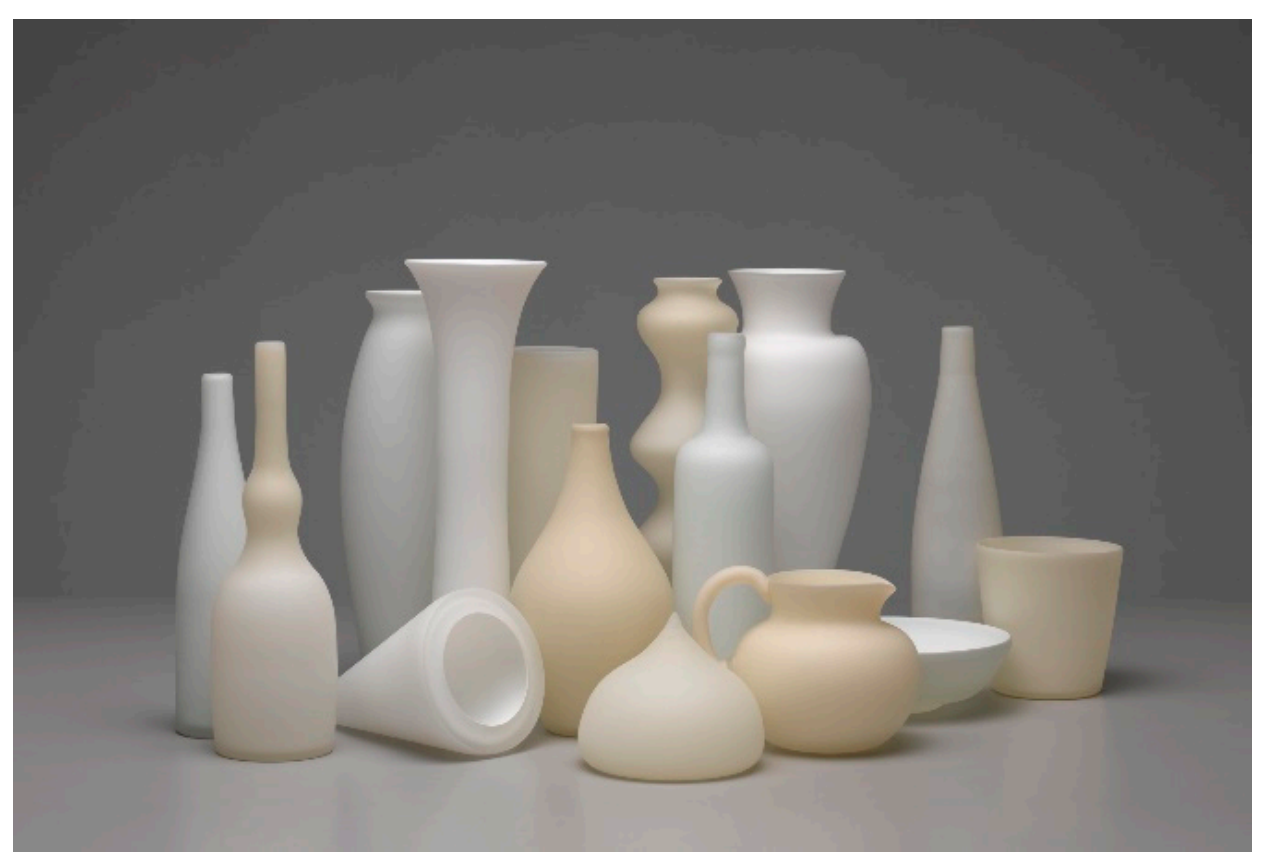

Figure 25. Image Courtesy of Wendy Fairclough, Four shades of white (2009), blown glass, Photo credit: The artist. H: $38 \mathrm{~cm}$; W: $63 \mathrm{~cm}$; D: $45 \mathrm{~cm}$. 


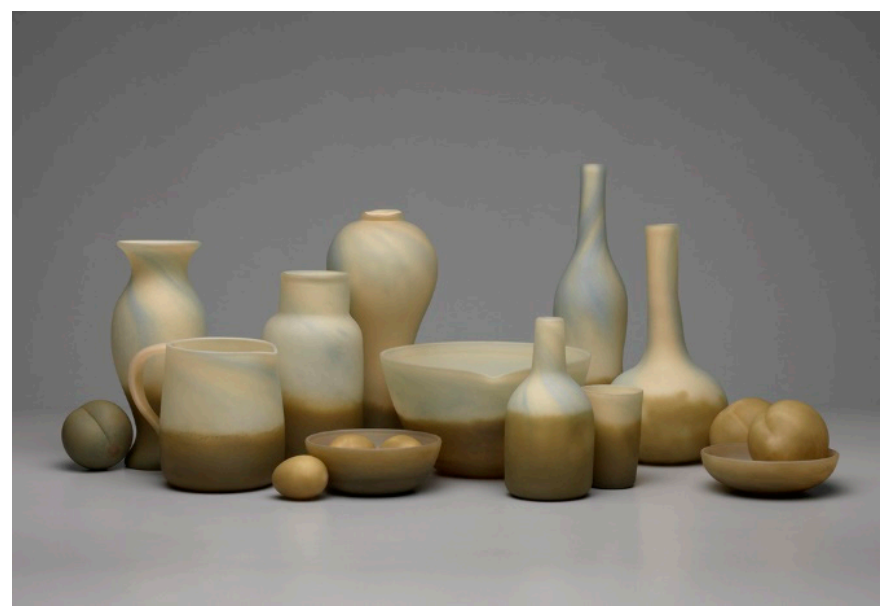

(a)

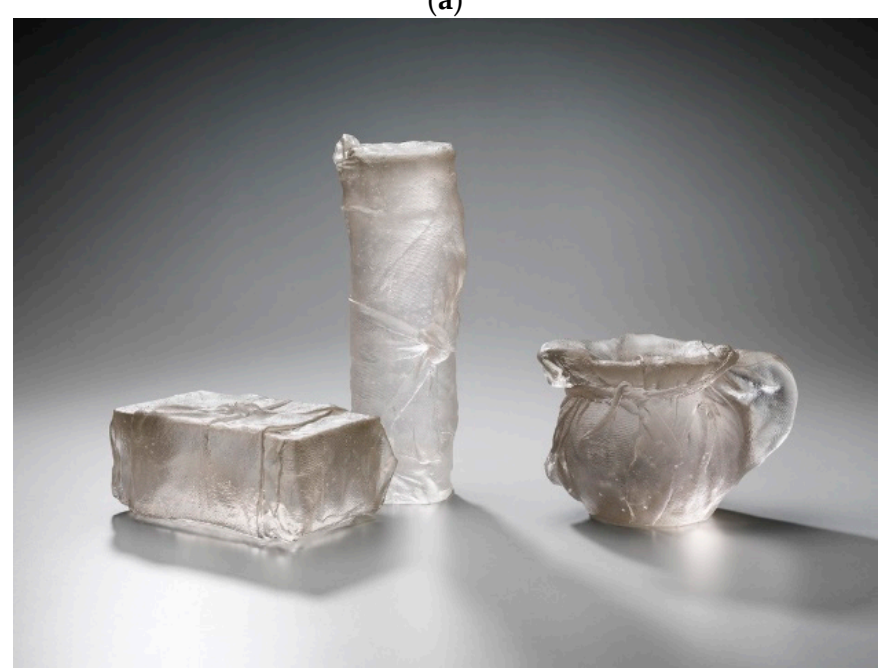

(b)

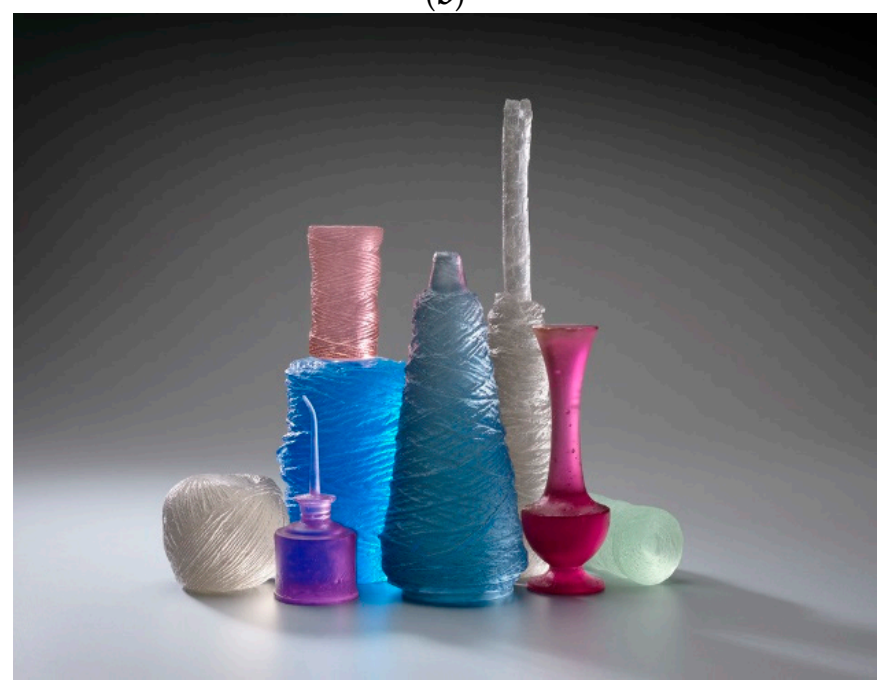

(c)

Figure 26. Image Courtesy of Wendy Fairclough, (a) Softened Landscape (2008), blown glass, coloured, Photo credit: The artist. H: $37.5 \mathrm{~cm}$; W: $118 \mathrm{~cm}$; D: $37.5 \mathrm{~cm}$; (b) Enfold (2014) kiln cast lead crystal, Photo credit: The artist. H: $24 \mathrm{~cm}$; W $46 \mathrm{~cm}$; D: $19 \mathrm{~cm}$; (c) Threads (2014) kiln cast lead crystal, Photo credit: The artist. H: $25 \mathrm{~cm}$; W: $25.5 \mathrm{~cm}$; D: $13 \mathrm{~cm}$. 


\section{Conclusions}

This paper has introduced the theme of imitation within the field of art glass. Many historical and contemporary glass artists have used glass to imitate and actively remediate other materials; such as semi-precious stones, metal, wood and ceramic. The materiality of an artefact can be confusing, as a viewer we may question the exact nature and composition of the material presented; yet as artists we are able to subvert the semiotics of the objects we make. By changing the material's appearance and borrowing qualities from other mediums we can subvert the object's meaning to create a new visual language for the discipline. As a glass artist, I am certainly not alone in my journey to harness the unique qualities of glass to imitate other materials. This paper has referenced a range of artists that remediate other materials in the medium of glass asserting that imitation and mimicry is an integral and vital creative act. I have shared my research interest contextualizing and framing the assertion of this paper that the use of imitation is a necessary and definitive act within creative artistic practice. The author encourages responses and collaboration from other like-minded professionals in the field who are interested in this area.

Funding: This research received no external funding.

Conflicts of Interest: The author declares no conflict of interest.

\section{References}

Bolter, Jay David, and Richard Grusin. 1999. Remediation: Understanding New Media. Cambridge: MIT Press. Bray, Charles. 1995. Dictionary of Glass. London: A\&C Black.

Bryne, Edmond. 2018. Artist Interview conversation by email with author. unpublished information. November 8 . Choi, Keeryong. 2018. Artist Interview conversation by email with author. unpublished information. November 3 . CMOG (Corning Museum of Glass). 2008. Glass of the Alchemists. Available online: https:/ /www.cmog.org/ publication/glass-alchemists-lead-crystal-gold-ruby-1650-1750 (accessed on 30 November 2018).

CMOG (Corning Museum of Glass). 2011. Exhibition, East Meets West Cross-Cultural Influences in Glassmaking in the 18th and 19th Centuries. Available online: https:/ /www.cmog.org/article/east-meets-west-crosscultural-influences-glassmaking-18th-and-19th-centuries (accessed on 23 November 2018).

CMOG (Corning Museum of Glass). 2013a. Available online: https:/ / www.cmog.org/article/gold-ruby-glass (accessed on 30 November 2018).

CMOG (Corning Museum of Glass). 2013b. Cameo Gem Collection. Available online: https:/ /www.cmog.org/ artwork/cameo-gem-portrait-emperor-augustus (accessed on 10 November 2018).

Dormer, Peter. 1997. The Culture of Craft: Status and Future (Studies in Design and Material Culture). Manchester: Manchester University Press.

Fairclough, Wendy. 2018. Artist Interview conversation by email with author. unpublished information. November 11.

Gogarty, Amy. 2007. 'Remediating Craft', an Essay within Utopic Impulses Contemporary Ceramics Practice. Vancouver: Ronsdale Press.

Gudenrath, William. 2016. The Techniques of Renaissance Venetian Glassworking, Corning Museum of Glass. Available online: renvenetian.cmog.org (accessed on 11 October 2018).

Kingery, William David. 1986. High-Technology Ceramics Past, Present and Future. Westerville: The American Ceramic Society.

Loibl, Werner. 2008. Itineraries of Glass Innovation: Johann Glauber and His follower Essay in 'Glass of the Alchemists'. Edited by Dedo Von Kerssenbrock. New York: Corning Museum of Glass.

Rumor, Maddalena. 2018. Alchemy between 2 Bridges. Available online: http://www.asor.org/anetoday/2018/ 05/Alchemy-Between-Two-Rivers (accessed on 4 February 2019). 
Stevens, Kati. 2018. Fake, Object Lessons. London: Bloomsbury.

Thyer, Graeme. 2018. Artist Interview conversation by email with author. unpublished information. November 26. Toso, Gianfraco. 2000. Murano A history of Glass. Italy: Arsenale Editrice.

Von Kerssenbrock-Krosigk, Dedo. 2008. Gold Ruby Glass, Essay in 'Glass of the Alchemists'. Edited by Dedo Von Kerssenbrock. New York: Corning Museum of Glass. 